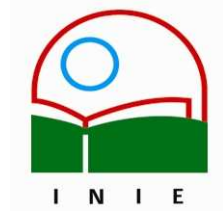

Actualidades Investigativas en Educación

Revista Electrónica publicada por el

Instituto de Investigación en Educación

Universidad de Costa Rica

ISSN 1409-4703

http://revista.inie.ucr.ac.cr

COSTA RICA

\title{
INFOCENTROS DEL MINISTERIO DE CIENCIA Y TECNOLOGÍA DE VENEZUELA Y SU GESTIÓN EDUCATIVA: ¿ALCANZAN LOS FINES PROPUESTOS?
}

THE INFO CENTRES OF THE SCIENCE AND TECHNOLOGY MINISTRY OF VENEZUELA AND THEIR EDUCATIVE MANAGEMENT: DO THEY REACH THE GOALS?

\author{
Volumen 8, Número 1 \\ pp. 1-31
}

Este número se publicó el 30 de abril 2008

\author{
Doris Parra \\ Jesús Cendrós \\ Niorka Medina
}

La revista está indexada en los directorios:

LATINDEX, REDALYC, IRESIE, CLASE, DIALNET, DOAJ, E-REVIST@S,

La revista está incluida en los sitios:

REDIE, RINACE, OEI, MAESTROTECA, HUASCARAN 


\title{
INFOCENTROS DEL MINISTERIO DE CIENCIA Y TECNOLOGÍA DE VENEZUELA Y SU GESTIÓN EDUCATIVA: ¿ALCANZAN LOS FINES PROPUESTOS?

\author{
THE INFO CENTRES OF THE SCIENCE AND TECHNOLOGY MINISTRY OF VENEZUELA \\ AND THEIR EDUCATIVE MANAGEMENT: DO THEY REACH THE GOALS?
}

\author{
Doris Parra ${ }^{1}$ \\ Jesús Cendrós ${ }^{2}$ \\ Niorka Medina ${ }^{3}$
}

\begin{abstract}
Resumen: Esta investigación se orienta a evaluar la gestión educativa de los infocentros del Ministerio de Ciencia y Tecnología de Venezuela. El tipo de investigación es descriptiva, cuantitativa y explicativa. Los instrumentos seleccionados para la recolección de la información son: entrevista al único supervisor y a 10 anfitriones y un cuestionario a los 290 usuarios de los infocentros estudiados. Los instrumentos se sometieron a validación de contenido por juicio de expertos. Se aplicó una prueba piloto con el cuestionario a una muestra intencional de 32 usuarios. Los datos recolectados se analizaron utilizando Análisis Factorial y Validez Discriminante para su validez de constructo y Alfa de Cronbach para su confiabilidad. Los resultados se analizaron considerando un Índice de alcance propio, media aritmética, desviación estándar, análisis de la varianza y prueba de múltiplos rangos de Tukey. Los resultados obtenidos indican que la gestión educativa de los infocentros resultó aceptable con un gran potencial, con muy buena receptividad por las comunidades y anfitriones especialmente como apoyo para utilizar las Tecnologías de Información y Comunicación como un instrumento potencial de desarrollo endógeno, cultural, social, económico y educativo.
\end{abstract}

Palabras Claves: GESTIÓN EDUCATIVA, INFOCENTROS, CIENCIA Y TECNOLOGÍA, COMUNIDADES.

\begin{abstract}
This investigation is oriented to evaluate the educative management of the info centres of Science and Technology Ministry of Venezuela. The type of investigation is descriptive, quantitative and explanatory. The instruments for collecting the data are: interview to the supervisor and 10 hosts and a questionnaire to 290 info center users. The instruments were validated by experts. A pilot test was made with the questionnaire to an intentional sample of thirty two (32) users. The collected data was analyzed using Factorial Analysis and Discriminate Validity for their validity of construct and Alpha Cronbach for trustworthiness. The results were analyzed using an index with own reach, arithmetic average, standard deviation, analysis of the variance and test of Tukey for multiple ranks. The results indicate that the educative management of the info centres was acceptable with a great potential, with very good receptivity by the communities and hosts, specially as a support to use the Technologies of Information and Communication as a potential instrument for endogenous, cultural, social, economic and educative development.
\end{abstract}

Key words: EDUCATIVE MANAGEMENT, INFO CENTRES, SCIENCE AND TECHNOLOGY, COMMUNITIES.

\footnotetext{
1 Profesora titular. Universidad Del Zulia. Facultad de Ingeniería. Maracaibo - Venezuela. Dirección electrónica: dorisparrach@cantv.net.

${ }^{2}$ Profesor titular Universidad del Zulia. Profesor contratado Universidad Rafael Belloso Chacín. Maracaibo - Venezuela. Dirección electrónica: jcendros@urbe.edu
}

3 Profesora titular. Universidad Del Zulia. Facultad de Ingeniería. Maracaibo - Venezuela. Dirección electronica: niorkamedina@cantv.net

Artículo recibido: 8 de febrero, 2008

Aprobado: 28 de abril, 2008 


\section{Introducción}

Venezuela, desde 1996, contrajo la tarea de proporcionar a todos los estratos sociales el acceso a las Tecnologías de la Información y Comunicación (TICs), mediante el desarrollo y creación de centros comunitarios con computadoras e Internet, llamados inicialmente cabinas públicas y posteriormente infocentros. El gobierno venezolano, entre 1998 y 1999 , inició un programa tentativo denominado Programa de Cabinas de Acceso Público (PCAP) a través del Centro Nacional de Tecnologías de Información (CNTI) organismo adscrito al Ministerio de Ciencia y Tecnología (MCT). Se inició con dos centros piloto localizados en bibliotecas metropolitanas en el área de Caracas (CNTI, 2001), siguiendo el modelo básico de franquicia centralizada y sin fines de lucro, con tarifas mínimas en todos los servicios, tanto en el acceso a Internet y uso de computadoras como en los otros servicios conexos como impresión, fotocopiadora y digitalización de documentos, lo cual brindaba un margen mínimo pero viable para la sustentabilidad financiera del programa (Barrera, 2002). Luego se sustituyó el programa de Cabinas de Acceso Público por el Programa Infocentros (PI), con cobertura nacional, construyendo o adecuando un espacio físico con condiciones de infraestructura mínimas con el fin de albergar equipos tecnológicos para permitir el uso de las TICs al ciudadano común.

Esta investigación se plantea como objetivo general evaluar la gestión educativa de los infocentros del MCT para las comunidades en el estado Zulia, por ser uno de los estados más representativos del país. En este sentido se plantean los siguientes objetivos específicos: 1) interpretar la filosofía de gestión del proyecto para confirmar su naturaleza, 2) diagnosticar las condiciones actuales de funcionamiento de los mismos, 3) establecer el nivel de democratización de los servicios educativos previstos en el proyecto y 4) determinar la sustentabilidad del programa en el estado Zulia.

La investigación pretende abrir un camino en el campo de la evaluación para esta modalidad educativa representada, en este caso, por los infocentros del MCT, investigación que, a pesar de ser reconocida como imperiosa, no había sido estudiada con rigurosidad científica. Se busca establecer una base para nuevas investigaciones de mayor envergadura. Así, su metodología conduce a advertir una realidad de la gestión educativa considerando un Índice de Alcance, sugerido por los autores, definido al medir un instrumento con diversidad de respuestas. Asimismo, la investigación aporta unos lineamientos que pueden servir como referencia para otros infocentros del país, pertenecientes o no a este proyecto, los cuales orientarían a los actores del programa en miras de mejorar su gestión. Por lo tanto, los resultados pueden servir de insumo para 
apoyar el desarrollo de un Plan Nacional dirigido a la creación de una plataforma tecnológica y educativa que proporcione un acceso democrático a las Tecnologías de Información y Comunicación (TICs); generando una infraestructura promotora de una sociedad de la información, a la par de una sociedad del conocimiento.

En el informe de la Comisión Internacional sobre la Educación, creada por la Organización de las Naciones Unidas para la Educación, la Ciencia y la Cultura (UNESCO) presidida por Delors y otros (1996, p.198) se señala con claridad la generación de una verdadera revolución que afecta tanto a las actividades relacionadas con la producción y el trabajo, como a las actividades ligadas a la educación y la formación, concluyendo que: “... las sociedades actuales son de uno u otro modo sociedades de información en las que el desarrollo de las tecnologías puede crear un entorno cultural y educativo capaz de diversificar las fuentes del conocimiento y del saber".

En este contexto, bajo la perspectiva de transformación y modernización constante, Pozner (2000, p.6) plantea que todas las organizaciones de un país “...se ven obligadas a revisar tanto las finalidades y las misiones que buscan cumplir en la sociedad, como sus modos de organizarse y funcionar para cumplir con sus finalidades".

Así, puede inferirse que en muchos países en expansión, la educación se enfrenta a procesos permanentes de cambio a corto, mediano y largo plazo. Estos desafíos, con el poder de la sociedad y del Estado, exigen proyectos, planes y programas sustentables que podrían generar las condiciones primarias de calidad referidas a capacidades científicas y docentes, planta física, equipamiento tecnológico, currículo integral, protección socioeconómica, participación de la familia y autonomía escolar. Todo esto permitiría conformar una oferta capaz de satisfacer gran parte de las demandas educativas de la sociedad.

\section{Programa Infocentros y su filosofía de gestión}

En el transcurso del año 2000, por mandato presidencial se sustituyó el programa de Cabinas de Acceso Público (PCAP) por el Programa Infocentros (PI). Al mismo tiempo se emitieron importantes medidas de carácter legislativo, como la promulgación de la nueva Ley Orgánica de Telecomunicaciones (Presidencia de la República Bolivariana de Venezuela, 2000b, p.1), el Articulo $1^{\circ}$ del Decreto 825 (Presidencia de la República Bolivariana de Venezuela, 2000a, p.1), el diseño del Plan Nacional de Tecnologías de Información y Comunicación (PlanTIC), a través del CNTI (Ministerio de Ciencia y Tecnología de Venezuela, 2001).

Todas las transformaciones normativas y legales anteriormente dichas, junto con el 
compromiso gubernamental, sirvieron como base para crear doscientos cuarenta y tres (243) infocentros en todo el territorio nacional, con una inversión inicial correspondiente a diecisiete mil millones de bolívares (Bs. 17.000.000.000), cuyo acceso gratuito proyectado es de siete millones doscientos mil (7.200.000) visitantes al año, el cual podría alcanzar a diez millones (10.000.000) de visitas a Internet en un año, especialmente de población con escasos recursos.

El Proyecto Infocentros (CNTI, 2000, p. 6), describe que:

Desde el punto de vista de infraestructura física y tecnológica, un infocentro es un lugar que se encuentra en un espacio físico que cumple con condiciones de infraestructura mínimas para albergar equipos tecnológicos que permiten el uso de nuevas tecnologías de información y comunicación (TICs). Sin embargo, desde el punto de vista filosófico y social es un lugar de encuentros ciudadanos, un espacio de participación e intercambio de conocimientos para el desarrollo individual y social, un lugar para resolver necesidades de información y comunicación sobre distintos aspectos relacionados a la educación, oportunidades de trabajo, entretenimiento y participación.

A pesar de que el proyecto responde a ciertas propuestas de gestión institucional de un organismo perteneciente al nivel central del Estado, el CNTI (2000, p. 7) consideró importante acotar que:

Los infocentros representan en sí mismos la posibilidad de convertirse en cierto tipo de organizaciones que estarían destinadas a perfilar sus propias características naturales y así, configurar su propia estrategia organizativa y de gestión, en tanto serían autónomas de una adscripción al MCT o al CNTI.

Pero, para poder garantizar la coherencia de objetivos de las políticas públicas en sus distintos niveles: nacionales, regionales y locales, el MCT estimó pertinente definir ciertas pautas de la filosofía de gestión, las cuales pueden conducir las acciones exitosas que se esperan de un infocentro, para ciertos casos puntuales (Vivas y Suros, 2000). Así, los principios orientadores se perfilan de acuerdo con los componentes de filosofía de gestión que son: su visión, misión, objetivos y valores.

La visión del Proyecto Infocentros (CNTI, 2000, p. 7) es que

...espera convertirse en un modelo de acción institucional que genere propuestas de carácter organizativo flexibles y abiertos a las posibilidades de gestión de y para el 
desarrollo regional y local, a través de distintas instancias y dinámicas de participación y acercamiento de las comunidades a las ventanas de oportunidad de las tecnologías de información, y, en definitiva, como organizaciones de aprendizaje por y para el desarrollo sustentable de Venezuela en procura del logro de una sólida sociedad del conocimiento que permita el intercambio internacional en condiciones de equidad y solidaridad social.

Por otro lado su misión es:

... convocar voluntades, acciones y propuestas para instaurar una nueva cultura de aprendizaje dentro de todos los niveles de desarrollo nacional, que de acuerdo a las especificidades del contexto social y cultural de cada comunidad permitiendo desarrollar una plataforma tecnológica y educativa que propicie un acceso más amplio y democrático de las nuevas tecnologías de información por parte de los sectores menos privilegiados de la población venezolana (CNTI, 2000, p. 8).

Los objetivos puntuales iniciales del PI (CNTI, 2000, p. 8), específicamente son:

1. Democratizar el acceso a Internet para que la mayoría de los venezolanos utilice esta nueva tecnología.

2. Capacitar y formar a las personas a través de nuevas metodologías de aprendizaje y contenidos teóricos acordes con las demandas específicas de cada comunidad de hospedaje.

3. Proveer información y asistencia técnica sobre oportunidades educativas y de negocios para reactivar el sector productivo local aprovechando las ventajas comparativas para convertirlas en ventajas competitivas en el contexto de la globalización.

4. Apoyar nuevas iniciativas empresariales a través de la promoción y difusión de los servicios que ofrecen dentro de la red de Internet.

5. Facilitar la gestión de servicios públicos a través del acceso a Internet.

6. Apoyar escuelas básicas y otros centros educativos formales e informales en la producción, procesamiento e intercambio de contenidos y metodologías educativas.

Y por último, el Proyecto Infocentros (CNTI, 2000, p. 8) pretende generar individuos con: (a) creatividad para emprender, aprender y hacer; (b) solidaridad social para la equidad; 
(c) conocimiento compartido para la acción colectiva; (d) calidad de Vida para la vida cotidiana y (e) sentido de pertenencia para fortalecer la identidad.

Por lo tanto, el éxito del proyecto depende del cumplimiento de su filosofía de gestión por parte de todos los involucrados y así garantizar la coherencia de objetivos de las políticas públicas en sus distintos niveles: nacionales, regionales y locales.

\section{Condiciones de funcionamiento de los infocentros}

Corresponden a la ubicación, infraestructura física, equipamiento tecnológico, conectividad, recursos humanos, fuentes de financiamiento y mantenimiento. La ubicación tiene que ver con el lugar apropiado escogido para su funcionamiento, el cual debe ser de fácil acceso a la comunidad y a los discapacitados; debe estar bien comunicado (en un lugar céntrico) y/o disponer de línea de transporte público y estacionamiento. Sería deseable su instalación en un inmueble independiente, bien iluminado y sin exceso de ruidos externos que perturben el ambiente de centro de enseñanza y de trabajo (AET, 2004).

La infraestructura física se refiere al tamaño, condiciones climáticas, distribución del espacio físico, horario de operatividad y diseño interior. Según la AET (2004), debe tomarse en cuenta, para las dimensiones de la planta, el número de usuarios que se espera recibir, el puesto para cada computador y la existencia de grandes espacios acristalados por la necesidad de iluminación.

El equipamiento tecnológico se relaciona con las computadoras, máquinas de fax, fotocopiadoras, teléfonos, etc. presentes. La conectividad se refiere a la tecnología utilizada para proveer la conectividad como utilización de la red de telefonía tanto fija como móvil celular, soluciones vía satélite, sistemas que utilizan radio VHF, etc. El recurso humano es un equipo de trabajo que debe cumplir con el perfil requerido por el proyecto y además, debe poseer un alto nivel de sensibilidad, compromiso, disposición y cumplimiento para prestar servicios a la comunidad.

Como fuentes de financiamiento se estudian los distintos orígenes del pago del costo de la instalación del infocentro; así como también, una vez instalado, las maneras de financiamiento que proporcionarían su sustentabilidad. Son muchos los servicios que puede ofrecer, como posibilidad de autofinanciamiento: desde telefonía pública hasta el acceso a Internet, pasando por servicios de secretaría, tratamiento de textos hasta telemedicina (López, 2002). 
El mantenimiento se relaciona con el costo de la infraestructura, de los servicios básicos, del equipamiento tecnológico, del material utilizado, de acceso a telefonía y a Internet; así como también al mantenimiento del equipamiento tecnológico.

Para el logro de los objetivos fundamentales del Programa Infocentros, se hace necesario un buen funcionamiento del mismo; por lo tanto, se deben cumplir el mayor número de las condiciones de funcionamiento antes planteadas.

\section{Democratización de los Servicios Educativos}

Según Vivas y Suros (2000), la prestación de servicios que debe ofrecer el infocentro es una extensión de las expresiones y vocaciones naturales requeridas por cada comunidad particular. López, (2002) manifiesta que todos deben estar dirigidos hacia la comunidad en general, aunque en la práctica los grupos que más uso hacen de ellos son los profesores y alumnos por parte de la comunidad educativa, funcionarios públicos y, los comerciantes y pequeños empresarios que los utilizan como pequeñas oficinas eventuales.

Muchas organizaciones han realizado encuentros, seminarios y talleres con el fin de promover la democratización de las TICs que repercutan en la calidad de vida de los ciudadanos, en especial, los sectores más empobrecidos de la sociedad. En la labor del infocentro de introducir las TICs, según López (2002), se podrían distinguir dos tipos de formación: una, la informática a nivel de usuario, la cual lo capacita para utilizar una computadora, navegar por Internet, enviar un correo electrónico, y que es ofrecida como una estrategia, con el objetivo de captar a usuarios inexpertos, y otra de nivel superior y específica, como el manejo de paquetes ofimáticos (procesamiento de palabras, hojas de cálculo, presentación) o la programación de páginas web, cuyo objetivo es la formación de profesionales.

Es importante destacar el papel que desempeñan los infocentros, no solo en la formación de particulares, sino también en dotar a instituciones públicas, organizaciones sociales, y empresas privadas con nuevas habilidades y capacidades. Estas organizaciones, generalmente ligadas con los entes promotores, son capaces de ir integrando las TICs en su funcionamiento y trabajo diario.

Por último, el desarrollo de sistemas de información y de contenidos se ha producido como respuesta a las necesidades de las propias comunidades o a través de la recopilación y almacenamiento del propio conocimiento local. Usualmente, la principal fuente de información para estos sistemas es Internet, pero esto acarrea varios inconvenientes pues, como dice Proenza y otros (2001), la información existente en los servidores en castellano es 
pobre y además, en muchos países la información disponible es muy limitada sobre localidades lejos de la ciudad capital y el país en general.

En el caso particular del Estado Zulia, los usuarios son poblaciones heterogéneas conformadas por niños y jóvenes provenientes de zonas urbanas, del área rural, fronterizas, indígenas y urbano-marginales las cuales no siempre encuentran sitios con información en su idioma y sobre tópicos de su interés. Luego, la prestación de servicios debe abocarse, en mayor medida, a la capacitación académica, la actualización académica, la formación para el trabajo, el crecimiento personal, la formación ciudadana y comunitaria y a la generación de contenidos educativos.

\section{Sustentabilidad}

Para la Organización Internacional del Trabajo, OIT (1996) la sustentabilidad de un programa o proyecto es una función de la durabilidad de sus efectos y resultados una vez que este haya finalizado y retirado el apoyo financiero externo. Esta entidad recomienda que para evaluar la sustentabilidad se debe analizar sobre: 1) las disposiciones tomadas a nivel institucional, 2) el suministro de los recursos humanos y materiales necesarios y 3) la preparación del personal local para asumir sus responsabilidades, entre otros, y así garantizar la continuación y/o ampliación del programa o proyecto.

En un sentido amplio, la sustentabilidad para el Programa Infocentros, se refiere a la viabilidad económica, tecnológica, social y política que permitan su funcionamiento en forma sistémica en el tiempo y en el espacio. Así lo entiende la Fundación Chasquinet (2002), una entidad sin fines de lucro dedicada a proveer soluciones de Internet a los individuos, instituciones y comunidades comprometidas con el cambio social en Ecuador y la región.

De acuerdo con diversas experiencias recabas por diferentes organismos, agencias y centros que tienen o cooperan con programas de centros comunitarios de acceso a Internet, tales como UNESCO, el CIID, el Banco Mundial, el Banco Interamericano de Desarrollo, entre otros, se pueden extraer varios factores claves para el manejo de la sustentabilidad, pero por estar íntimamente interrelacionados y ser interdependientes los esfuerzos requeridos para promover el desarrollo de los infocentros, los autores consideran que se deben enfocar de una manera más global e integral.

En consecuencia, en relación con este estudio del Programa Infocentros del MCT ubicados en el Estado Zulia, se especificaron tres indicadores con el fin de determinar su sustentabilidad, los cuales son: asociatividad, competitividad y expansividad. 
Según Rosales (1997), la asociatividad puede definirse como “......un mecanismo de cooperación entre empresas pequeñas y medianas, en donde cada empresa participante, manteniendo su independencia jurídica y autonomía gerencial, decide voluntariamente participar en un esfuerzo conjunto con los otros participantes para la búsqueda de un objetivo común" (p. 97). Por lo tanto, el Programa Infocentros deberá demostrar su capacidad para generar relaciones de cooperación, de constituir vínculos y fortalecer los nexos con las comunidades y con los otros infocentros. En la medida que lo anteriormente se cumpla, en esa misma medida se le dará la continuidad a su existencia, en relación a la asociatividad.

En cuanto a la competitividad, Assenza (1999) opina que

......nadie puede oponerse a la competencia profesional, a la autonomía institucional o, mucho menos, a la diversidad, cuando éstas se fundan en irrefutables investigaciones e innovaciones educativas, en procesos transparentes y continuos de participación y construcción democrática, de los diversos actores sociales, que decodifican, y representan éticamente las necesidades de la comunidad (p. 15).

Se puede entender la competitividad como la capacidad de los infocentros para optimizar su gestión, como un recurso que les permita disfrutar y sostener en el tiempo un posicionamiento en el entorno en el que actúan. En la medida en que la competitividad sea una de las dinámicas que mantenga vivo a los infocentros, será una de las condiciones necesarias para que ellos perduren en el tiempo, crezcan y satisfagan las necesidades de todos sus usuarios. Esta capacidad de competir se basa en descubrir oportunidades antes que las mismas se hagan manifiestas y desarrollar e incorporar habilidades distintivas que se constituyan en ventajas competitivas.

En definitiva, la competitividad del Programa Infocentros será el resultado de sumar calidad, innovación y productividad producido por todos los actores del proyecto para permanecer en el mercado, para lograr su sustentabilidad y desarrollo socioeconómico, político y tecnológico a largo plazo.

Porter (1993) teoriza diciendo que "el adquirir ventaja competitiva exige que la cadena de valor de una empresa se gestione como un sistema y no como una colección de partes separadas (p. 74)". En cuanto a las posibilidades de multiplicación, para Proenza y otros (2001), "La factibilidad de reproducir una experiencia en gran escala entre la población meta requiere que un modelo de telecentros sea adaptable a condiciones variadas con relativa facilidad' (p. 7). Así, entonces la expansividad del Programa Infocentros se mide por la facultad de existir una coordinación interinstitucional y por su reestructuración sustancial. 


\section{Aspectos Metodológicos}

Los fundamentos teóricos, anteriormente expuestos, permitieron operacionalizar la variable gestión educativa de los infocentros del MCT estableciendo cuatro dimensiones: 1) filosofía de gestión del proyecto con los indicadores: visión, misión, objetivos y valores; 2) condiciones de funcionamiento con los indicadores: ubicación, infraestructura física, equipamiento tecnológico, conectividad, recursos humanos, fuentes de financiamiento y mantenimiento; 3) democratización de los servicios educativos con los indicadores: capacitación académica, actualización académica, formación para el trabajo, crecimiento personal, formación ciudadana y comunitaria y, generación de contenidos educativos; y 4) sustentabilidad del Programa Infocentros con los indicadores: asociatividad, competitividad y expansividad.

Los indicadores de la variable fueron medidos en una sola oportunidad, durante el período comprendido entre febrero de 2003 y julio de 2004.

El estado Zulia tiene 2.983.679 habitantes de los 23.232.553 totales de Venezuela (INE, 2002) representando el estado con mayor población del país $(12,84 \%)$ y cuenta con 15 infocentros de los 243 instalados en todo el país, de los cuales solo estaban funcionando 10 para el momento del estudio. Por lo tanto, la población de estudio quedó conformada por los diez (10) infocentros activos, quedando por municipios como lo muestra el Cuadro 1.

\section{Cuadro 1 \\ Infocentros activos estudiados por municipio}

\begin{tabular}{|l|c|}
\hline \multicolumn{1}{|c|}{ INFOCENTRO } & MUNICIPIO \\
\hline Centro de Arte Maracaibo Lía Bermúdez & Maracaibo \\
\hline Acervo Histórico de Estado & Maracaibo \\
\hline Biblioteca Pública Gilmer Fernández & San Francisco \\
\hline Casa de la Cultura Gabriel Bracho & Miranda \\
\hline Biblioteca Pública Simón Bolívar & Cabimas \\
\hline Instituto Autónomo de Cultura & Simón Bolívar \\
\hline Ateneo Fronterizo de la Guajira & Páez \\
\hline Biblioteca Pública Omar Baralt & Mara \\
\hline Casa de la Cultura Manuel Antonio López & Rosario de Perijá \\
\hline Biblioteca Pública Municipal Br Armando Colina & Machiques de Perijá \\
\hline
\end{tabular}

Fuente: Ministerio de Ciencia y Tecnología, 2004 
El muestreo fue intencional; se escogió un (1) supervisor asignado por el MCT y es el único que cumple esa función para todos los infocentros en el estado Zulia; un (1) anfitrión por cada uno, resultando un total de diez (10) anfitriones y al inicio se seleccionaron 32 usuarios por infocentro, pues fue el número promedio diario de asistentes durante los últimos 6 meses al de la Casa de la Cultura Gabriel Bracho, resultando un total de 320 usuarios. Se validó el número de la muestra de los usuarios, utilizando la fórmula propuesta por Sierra (1979, citado por Chávez 2001):

$$
n=p(1-p)\left(\frac{Z}{E}\right)^{2}=(0.1)(0.9)\left(\frac{1.96}{0.11}\right)^{2}=29
$$

donde: $\mathrm{p}=$ proporción estimada basada en los usuarios pertenecientes al estrato socioeconómico IV y V, calculado por el método de Graffar modificado por Méndez Castellano (1985, citado por Ruiz 2002), $Z$ = valor asociado con el nivel de confianza deseado para el $95 \%$ y $E$ = error máximo tolerado por los autores. La distribución censal definitiva se muestra en el Cuadro 2.

Cuadro 2

Distribución censal

\begin{tabular}{|l|c|c|}
\hline \multicolumn{1}{|c|}{ INFOrixa Márquez } & \multicolumn{2}{c|}{ Un (1) Supervisor } \\
\hline Ateneo Fronterizo de la Guajira & Anfitrión & Usuarios \\
\hline Biblioteca Pública Omar Baralt & 1 & 29 \\
\hline Biblioteca Pública Gilmer Fernández & 1 & 29 \\
\hline Casa de la Cultura Manuel Antonio López & 1 & 29 \\
\hline Centro de Arte Maracaibo Lía Bermúdez & 1 & 29 \\
\hline Instituto Autónomo de Cultura & 1 & 29 \\
\hline Acervo Histórico de Estado & 1 & 29 \\
\hline Biblioteca Pública Simón Bolívar & 1 & 29 \\
\hline Casa de la Cultura Gabriel Bracho & 1 & 29 \\
\hline Biblioteca Pública Municipal Br Armando Colina & 1 & 29 \\
\hline & 1 & 29 \\
\hline
\end{tabular}

Fuente: Parra, 2004

Se seleccionaron como instrumentos de recolección: (a) la técnica de análisis documental y una entrevista no estructurada al supervisor (IS) constituida por 16 preguntas para obtener información acerca de la filosofía de gestión y sustentabilidad del PI y sus 
indicadores respectivos; (b) una entrevista no estructurada a los anfitriones activos (IA) compuesta por 32 preguntas para diagnosticar las condiciones actuales de funcionamiento y sustentabilidad de los mismos con sus indicadores, y (c) la técnica de la encuesta tipo cuestionario mixto a los usuarios (IU) compuesta por 20 preguntas, algunas abiertas y otras cerradas o semi-cerradas para diagnosticar las condiciones actuales de funcionamiento en Ios indicadores: ubicación y fuentes de financiamiento, establecer el nivel de democratización de los servicios educativos y sustentabilidad con sus indicadores respectivos.

La validez de contenido del cuestionario fue emitida por el juicio de siete (7) doctores expertos en el área de Metodología de la Investigación y en Ciencias de la Educación. La confiabilidad del cuestionario se determinó a través de una prueba piloto aplicada a la muestra de 32 usuarios. Para el cálculo de la confiabilidad numérica del cuestionario hubo que codificar los datos debido a la variedad de respuestas existentes en la base de datos. Así, los autores crearon el Índice de Alcance, el cual se definió como el porcentaje del total de atributos o características considerados como positivos, óptimos o ideales de una dimensión y/o indicador que tipifican al infocentro. Estos atributos son los que están contemplados en las preguntas de los instrumentos, considerados de manera que lo beneficien en términos de su desarrollo o alcance de sus objetivos; es decir, mientras más de estos posea, mayor será el índice de alcance.

Una vez estandarizados los datos de la prueba piloto y a cuyos resultados se les aplicó el coeficiente Alfa de Cronbach, utilizando el paquete estadístico Statistical Package for Social Science (SPSS) para Windows (versión 10.0), se obtuvo el valor del coeficiente que resultó ser 0.94360 , el cual indica que el cuestionario tiene una confiabilidad numérica muy alta; por lo tanto, sus resultados tienen una alta probabilidad de ser confiables.

Se elaboraron los instrumentos definitivos y se procedió al análisis descriptivo de los resultados; se digitalizaron con Microsoft Office Excel 2003 y procesaron con el SPSS versión 10 para el análisis estadístico mediante la Media y Desviación Estándar, Análisis de la Varianza (ANOVA) y Prueba de Múltiples Rangos de Tukey, con el objetivo de obtener la información sobre la gestión educativa de los infocentros del MCT en el estado Zulia.

\section{Análisis y Discusión de los Resultados}

Los resultados de la entrevista no estructurada al anfitrión (IA), al supervisor (IS) y del cuestionario aplicado a los usuarios (IU) de los infocentros del MCT en el estado Zulia, se estructuraron y se mostraron en dos partes: una correspondiente a la información general de 
los usuarios y anfitriones, y otra concerniente a los enunciados de las dimensiones de la variable estudiada: gestión educativa.

En el infocentro del Instituto Autónomo de la Cultura, localizado en Tía Juana capital del municipio Simón Bolívar del estado Zulia, se imparten cursos de Internet, computación básica, Office, capacitación docente y cocina virtual; siendo, computación básica uno de los cursos más demandados por la comunidad. Entre las debilidades citadas por la anfitriona en el IA resaltan la lentitud de la conectividad, la falta de un buen acondicionamiento de aire (tienen que utilizar un abanico para ayudar a la ventilación), la insuficiencia de ingresos económicos, la falta de supervisión y de capacitación a los anfitriones por parte de la Gobernación del estado Zulia y del CNTI. Entre las impresiones de los usuarios se destaca la gran ayuda gratuita que proporciona a las personas de bajos recursos en su formación y estudio; de las debilidades se distinguen la lentitud de conexión, poca cantidad de cursos ofrecidos y el deficiente desempeño del acondicionador de aire. La anfitriona solicita fotocopiadora, trascripción de trabajos, aumento en las tarifas de servicios conexos, venta de refrescos y chucherías e innovación de cursos como medio de autogestión.

En el infocentro de la Biblioteca Pública Omar Baralt, localizado en San Rafael de EI Moján capital del municipio Mara del estado Zulia, se han impartido cursos de Internet a los estudiantes de la Universidad Católica Cecilio Acosta (UNICA) y entre los cursos no existentes más demandados por la comunidad se encuentra el manejo de Office. Entre las debilidades citadas por el anfitrión resaltan la insuficiencia de ingresos económicos, falta de supervisión y, de dolientes e intromisión política por parte de la Gobernación y del CNTI, insuficiencia de equipos y de personal, así como la dependencia que tiene del aire acondicionado de la biblioteca lo cual genera un entorpecimiento de sus labores. Entre las impresiones de los usuarios resalta la gran ayuda gratuita que proporciona a las personas de bajos recursos en su formación y estudio; entre las debilidades destacan la poca cantidad de cursos, falta de computadoras y de chat, poco tiempo de conexión, personal poco capacitado y poco tiempo ofrecido en el horario de visita. El anfitrión solicita la apertura de otros servicios de Internet, funcionamiento los sábados, cursos para la comunidad, fotocopiadora y cobro por tiempo adicional como medios de autogestión. Este infocentro tiene, junto con un grupo de jóvenes de la comunidad, un proyecto comunitario de ayuda al mismo, que presentarán a las autoridades cuyo nombre es "Jóvenes luchadores por Mara". Opinan que los entes gubernamentales no conocen el potencial de los infocentros.

En el de la Biblioteca Pública Gilmer Fernández, localizado en San Francisco capital del municipio San Francisco del estado Zulia, se imparten cursos de Internet y de manejo de 
Office, entre los cursos no existentes más demandados por la comunidad se encuentra Internet y Office avanzado. Entre las debilidades citadas por el anfitrión resaltan la lentitud de la conectividad, el mal funcionamiento del aire acondicionamiento, falta de vigilancia, ausencia de personal para la limpieza del local, poco acceso y publicidad del infocentro, falta de dolientes gubernamentales, así como la falta de capacitación de los anfitriones. Entre las impresiones de los usuarios resalta, al igual que los anteriores, es la gran ayuda gratuita que proporciona a las personas de bajos recursos en su formación y estudio; de las debilidades destacan el poco tiempo de conexión, mala atención y maltrato del anfitrión del turno de la mañana y, poca publicidad del mismo.

El personal del Centro de Arte de Maracaibo Lía Bermúdez, localizado en Maracaibo capital del municipio Maracaibo del estado Zulia, no imparte cursos; sin embargo, presta servicios a escuelas que los requieran ofreciendo el espacio para los docentes y alumnos. De los cursos no existentes el más demandado por la comunidad es el de computación. Entre las debilidades citadas por el anfitrión resaltan la lentitud de la conectividad, la falta de fotocopiadora, la insuficiencia de equipos e ingresos económicos, intervenciones políticas, así como la falta de capacitación de los anfitriones. Entre las impresiones de los usuarios resalta la gran ayuda gratuita que proporciona a las personas de bajos recursos en su formación y estudio; de las debilidades destacan ausencia de cursos, falta de computadoras, poco tiempo en el horario de atención, conexión lenta y poco tiempo de conexión. El anfitrión solicita aumento en las tarifas de servicios conexos, fotocopiadora y apoyo financiero por parte de la Gobernación y empresas privadas como medios de gestión y que los entes gubernamentales escuchen sus necesidades y peticiones.

En el infocentro de la Biblioteca Pública Municipal Bachiller Armando Colina, localizado en Machiques capital del municipio Machiques de Perijá del estado Zulia, se imparten cursos de computación básica, computación básica para educadores e Internet como herramienta pedagógica, entre los cursos no existentes más demandados por la comunidad se encuentran el de computación avanzada y el de Internet. Entre las deficiencias citadas por la anfitriona resaltan la ausencia de manejo de dinero, falta de apoyo financiero, falta de supervisión y control del CNTI y de la Gobernación. Entre las impresiones de los usuarios, se repite la gran ayuda gratuita que proporciona a las personas de bajos recursos en su formación y estudio en un pueblo tan apartado de la capital; de las debilidades destacan ausencia de servicios conexos, falta de computadoras, poco tiempo de conexión, poco tiempo en el horario de atención. La anfitriona solicita la implantación de servicios conexos, 
su capacitación para el dictado de cursos, servicios de alquiler a empresas y venta de insumos como medios de autogestión.

En el del Acervo Histórico del Estado, localizado en Maracaibo capital del municipio Maracaibo del estado Zulia, se ha impartido el curso de Introducción a la Computación para los empleados del Acervo. Entre los cursos no existentes más demandados por la comunidad se encuentran el manejo de Office, Internet Avanzado y Diseño de Páginas Web. Entre las deficiencias citadas por el anfitrión resaltan la lentitud de la conectividad, la insuficiencia de ingresos económicos, así como la falta de capacitación de los anfitriones. Entre las impresiones de los usuarios resaltan, reiteradamente, están la gran ayuda gratuita que proporciona a las personas de bajos recursos en su formación y estudio y en especial, la ayuda profesional de los Anfitriones; de las debilidades destacan ausencia de cursos e insumos, lentitud y poco tiempo de conexión. El anfitrión solicita que les proporcionen insumos, lo capaciten para el dictado de cursos y talleres como medios de autogestión, un buzón de sugerencias para escuchar a la comunidad y que los entes gubernamentales no dejen morir el proyecto.

En el de la Biblioteca Pública Simón Bolívar, localizado en Cabimas capital del municipio Cabimas del estado Zulia, se han impartido cursos de Internet, computación básica y capacitación docente, siendo computación básica el más demandado por la comunidad y entre los cursos no existentes se destaca el de Diseño de Páginas Web. Entre las deficiencias citadas por la anfitriona resaltan la falta de acondicionamiento: iluminación y aire acondicionado (la ventilación se ayuda con un abanico), horario de atención muy reducido, lentitud en la conectividad, insuficiencia de ingresos económicos, así como la falta de capacitación de los anfitriones. Entre las impresiones de los usuarios resalta la gran ayuda gratuita que proporciona, en especial de la anfitriona, a las personas de bajos recursos en su formación y estudio; de las debilidades destacan el poco espacio y equipos, ausencia de cursos, mala conexión, poco tiempo de horario de atención y de conexión. La anfitriona solicita que participe la comunidad activamente, la realización de verbenas, cancelación de servicio de Internet después de una (1) hora gratuita y ofrecer servicios de fotocopiadora como medios de autogestión.

El personal del infocentro de la Casa de la Cultura Gabriel Bracho, localizado en Los Puertos de Altagracia capital del municipio Miranda del estado Zulia, imparte cursos sobre Internet básico, Taller de Información sobre Computadoras, Operador Básico de Computadora, Manejo de Office, Computación Básica para Educadores e Internet como Herramienta Pedagógica. Entre los cursos existentes más demandados por la comunidad se 
encuentran el manejo de Office e Internet y entre los no existentes están Corell Draw, Photoshop y Visual Basic. Entre las deficiencias citadas por la anfitriona resaltan la falta de espacio y mal funcionamiento del aire acondicionado, insuficiencia de equipos, ausencia de herramientas de programación, programas no actualizados, desatención por parte de los entes gubernamentales así como la falta de capacitación de los anfitriones y de publicidad. Entre las impresiones de los usuarios resalta la gran ayuda gratuita que proporciona a las personas de bajos recursos en su formación y estudio; de las debilidades destacan el poco espacio y equipos, mala conexión y poco tiempo de horario de conexión. La anfitriona solicita que haya otro anfitrión, una aula para dictar clases, una mejor remuneración y como medios de autogestión la realización de otros cursos, cancelación de servicio de Internet después de la media (1/2) hora gratuita y ofrecer servicios de quemador de CDs. Opina que los mismos están subutilizados y que pueden ser centros de capacitación.

El personal del infocentro de la Casa de la Cultura Manuel Antonio López, localizado en La Villa del Rosario capital del municipio Rosario de Perijá del estado Zulia, imparte cursos de Internet básico, manejo de Office, Computación Básica para Educadores e Internet como Herramienta Pedagógica. Entre los cursos existentes más demandados por la comunidad se encuentran Internet básico y el manejo de Office y, entre los cursos no existentes se encuentran Corell Draw y Autocad. Entre las debilidades citadas por el anfitrión resalta la insuficiencia de soporte financiero. Entre las impresiones de los usuarios resalta la gran ayuda gratuita que proporciona el infocentro a las personas de bajos recursos en su formación y estudio, recomiendan que haya otros infocentros en la región y de las debilidades destaca la mala conexión. El anfitrión solicita que haya realización de otros cursos y talleres como medio de autogestión.

El personal del infocentro del Ateneo Fronterizo de la Guajira (FUS), localizado en Sinamaica capital del municipio Páez del estado Zulia, ha impartido cursos de Windows básico a los estudiantes de la Universidad Católica Cecilio Acosta (UNICA), siendo el diseño de Páginas Web el curso no existente más demandado por la comunidad. Entre las debilidades citadas por el anfitrión resaltan la insuficiencia de ingresos económicos, desvinculación de la comunidad, la falta de organización y acuerdo entre los entes gubernamentales pues existe una rivalidad política entre ellos que la manifiestan en su operatividad y su desconocimiento de las funciones de los entes gubernamentales. Entre las impresiones de los usuarios resalta la gran ayuda y gratuita que proporciona, sobre todo de los anfitriones, a las personas de bajos recursos en su formación y estudio; de las debilidades destaca el poco tiempo de horario de conexión. El anfitrión solicita que no haya 
inclusión política en el programa y como medio de autogestión que haya venta de papelería, centro de comunicación de llamadas y servicio de fotocopiadora.

Con la finalidad de lograr el objetivo general de evaluar la gestión educativa de los infocentros del Ministerio de Ciencia y Tecnología en el estado Zulia, se desagregó el análisis y discusión que a continuación se desarrolla, en función de las dimensiones e indicadores que estructuran la variable. Para ello, se estableció un baremo de categorización de los índices de alcance de los atributos dependiendo del valor obtenido de la media aritmética de la variable, dimensión o indicador, como se muestra en el Cuadro 3.

\section{Cuadro 3}

Baremo de los índices de alcance de los atributos

\begin{tabular}{|c|c|}
\hline RANGO & CATEGORÍA \\
\hline $0-25$ & Inadecuada \\
\hline $25.1-50$ & Moderadamente Inadecuada \\
\hline $50.1-75$ & Moderadamente Adecuada \\
\hline $75.1-100$ & Adecuada \\
\hline
\end{tabular}

Fuente: Parra, 2004

En relación con el objetivo 1, donde se planteó interpretar la filosofía de gestión del Proyecto Infocentros para confirmar su naturaleza, según opinión del supervisor del MCT en el estado Zulia, el cumplimiento de la filosofía de gestión del proyecto se considera moderadamente adecuado, en conformidad con lo pautado en el Cuadro 3, ya que su índice de alcance resultó ser de $59.87 \%$, producto del promedio de los índices de alcance resultante de la visión, misión, objetivos y valores como se pueden observar en el Gráfico 1. En él puede verse que el indicador visión resultó ser categorizado como moderadamente inadecuado, misión y objetivos como moderadamente adecuados y valores como adecuado.

Gráfico 1.

Índices de alcance de los indicadores de la filosofía de gestión

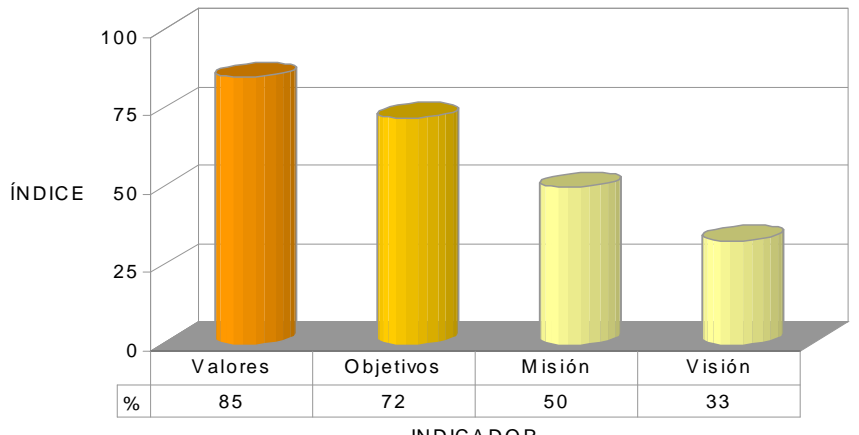

Fuente: Parra, 2004 
Para confirmar la naturaleza de la filosofía de gestión del proyecto, según Brugger (1995), es necesario discutir si el proyecto actualmente corresponde con el modo de ser para el cual fue diseñado. Además, experiencias en todo el mundo revelan que detrás de este tipo de organización exitosa hay una persona entusiasta y comprometida personalmente con el logro de la iniciativa y conocedora de la localidad y la comunidad en que trabaja (Proenza y otros, 2001). Quintero (2004), señala que la filosofía de gestión de los infocentros expresa su direccionamiento estratégico, en el que su viabilidad descansa sobre la contribución individual de cada uno de sus miembros y por lo tanto se requiere la identificación y el alto compromiso de sus líderes con el proyecto.

Los resultados evidencian que están generando moderadamente inadecuadas propuestas de carácter organizativo de aprendizaje por y para el desarrollo sustentable del país y, en la búsqueda de una sólida sociedad del conocimiento que permita el intercambio internacional en condiciones de equidad y solidaridad social establecidas en la visión del proyecto.

Asimismo, en su misión se están convocando moderadamente inadecuadas las voluntades, acciones y propuestas para desarrollar una plataforma tecnológica y educativa que propicie un acceso más amplio y democrático de las TICs por parte de los sectores menos privilegiados de la población venezolana.

Entre sus objetivos, está haciendo un moderadamente adecuado ofrecimiento a la capacitación y formación acordes a las demandas específicas de cada comunidad de hospedaje, a la asistencia técnica sobre oportunidades educativas y a la facilidad para la gestión de servicios públicos. Igualmente brinda un moderadamente adecuado apoyo a las escuelas básicas y otros centros educativos formales en la producción y procesamiento de metodologías educativas, no está ofreciendo la asistencia técnica sobre oportunidades de negocios, ni en la promoción y difusión a los servicios de las empresas venezolanas. De la misma manera no está apoyando a las escuelas básicas en el intercambio de metodologías educativas ni a otros centros educativos formales en el intercambio de metodologías y contenidos educativos. Por último, el proyecto no está ofreciendo ningún apoyo a los centros educativos no formales.

El aspecto menos favorecido de los valores resultó ser el relativo a que no genera individuos con sentido de pertenencia para fortalecer la identidad.

Según el CNTI (2001), el PI se estructuró como una iniciativa de promoción del MCT para la incorporación masiva a la tecnología, con el fin de favorecer un acceso democrático y disminuir las desigualdades que entorpecen el desarrollo de Venezuela. Sin embargo, según 
información emanada de la supervisora entrevistada, los infocentros en el estado Zulia fueron instalados por el CNTI en conjunto con la gobernación del estado en espacios disponibles $\mathrm{y}$ ofrecidos por los entes sin haber existido un estudio exhaustivo sobre la infraestructura física (en algunos no existían las requeridas por el proyecto) y sin la participación de las comunidades.

En relación con el objetivo 2, donde se propuso diagnosticar las condiciones actuales de funcionamiento, se destaca que estas se pueden catalogar como moderadamente adecuadas. Esto obedece al promedio obtenido entre los índices de alcance resultantes de: ubicación, infraestructura física, equipamiento tecnológico, conectividad, recursos humanos, fuentes de financiamiento y mantenimiento, que resultó ser del 66.75 con una desviación estándar del 5.25\% resultando los indicadores mantenimiento y ubicación categorizados como moderadamente inadecuados, equipamiento tecnológico y conectividad como moderadamente adecuados e infraestructura física, recursos humanos y fuentes de financiamiento como adecuados.

Para ver si los indicadores de la dimensión condiciones actuales de funcionamiento difieren significativamente entre sí, se le aplicó ANOVA, resultando que sí existen diferencias significativamente entre ellos ya que el valor de $\mathrm{F}=930.49$ con Sig. $=0.0000$ menor a 0.01 . Tal significancia, logra precisarse con la prueba de múltiples rangos de Tukey expresado en el Gráfico 2 por la diferencia cromática.

\section{Gráfico 2.}

Prueba de múltiples rangos de Tukey para los índices de alcance de los indicadores de las condiciones actuales de funcionamiento

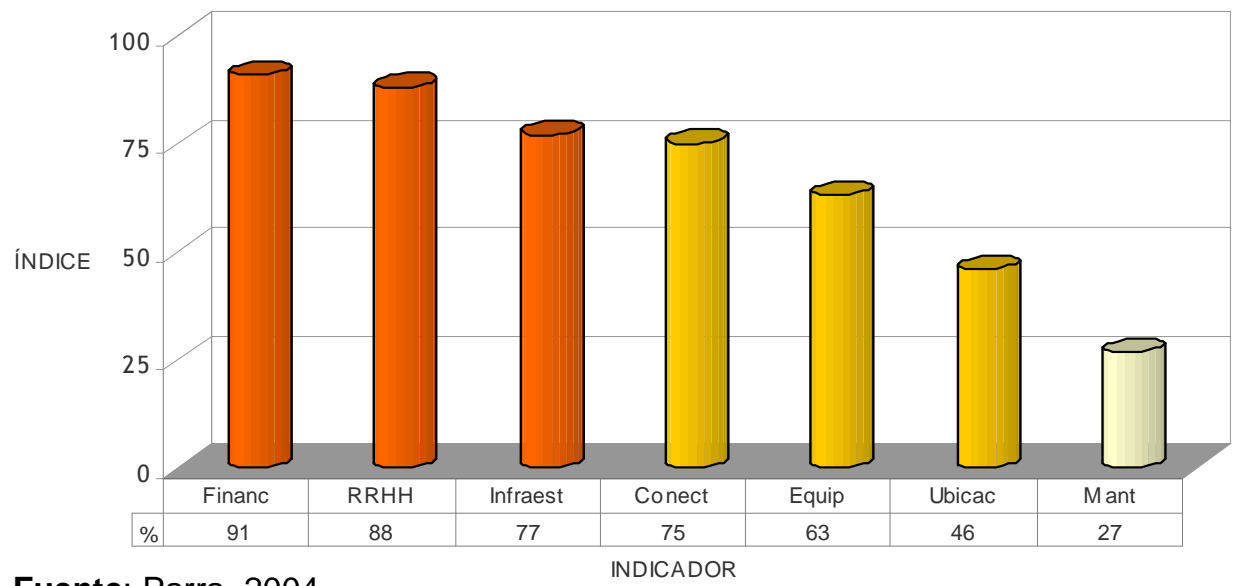

Fuente: Parra, 2004 
Como puede observarse el mantenimiento y ubicación resultaron los indicadores menos favorecidos. En cuanto al mantenimiento, según el proyecto (CNTI, 2000), la institución huésped acarrearía con costos de la infraestructura, servicio eléctrico, limpieza y fumigación, lo cual se cumple medianamente en su mayoría. De la pintura del local se ha encargado el CNTI una vez en los 3 años, el pago de los anfitriones en su mayoría lo hace la gobernación del estado o la alcaldía del municipio. No hay servicio telefónico y el servicio de conexión de Internet lo costea el CNTI. El mantenimiento del mobiliario y aire acondicionado se ha asumido por autogestión. El mantenimiento del computador es realizado, con muchas dificultades pero de muy buena calidad, por el técnico de los infocentros del MCT en el estado Zulia y por la empresa suplidora pues hay con ella una garantía de 3 años (a punto de terminarse) $y$, a las impresoras y al digitalizador nunca se les han suministrado mantenimiento (Entrevista realizada a Palmar, V. jefe del mantenimiento técnico de los infocentros del Ministerio de Ciencia y Tecnología en el estado Zulia el 13 de marzo de 2003 y actualizada 15 de abril de 2007).

En relación a la ubicación, los resultados de esta investigación evidencian que no se cumplen a cabalidad las condiciones de fácil acceso a la comunidad y a discapacitados para que, según la AET (2004) y el infocentro (CNTI, 2000), tenga buena ubicación. En ningún caso estudiado existen condiciones de acceso para discapacitados (algunos están ubicados en un segundo piso sin ascensor) y ciertos están ubicados lejos de comunidades o sin acceso de transporte público. Estos resultados permiten expresar que, de intentar en un tiempo cercano la mejoría de las condiciones de funcionamiento, en procura de optimizar su gestión educativa, debe dársele prioridad al mantenimiento, después a ubicación, equipamiento tecnológico, conectividad, infraestructura física, recursos humanos y fuentes de financiamiento. Es importante acotar que las fuentes de financiamiento resultaron adecuadas debido a que el gobierno nacional o regional o los entes donde residen los infocentros aún los financian.

Para ver si existen diferencias significativas entre las condiciones actuales de funcionamiento de los infocentros estudiados, se les aplicó ANOVA resultando que sí difieren significativamente entre ellos ya que el valor de $F=20.54$ es altamente significativo a $p$ menor a 0.01 y tal diferencia se discrimina con la prueba de Tukey mostrada en el Gráfico 3 por la diferencia cromática. Los que mostraron mejores condiciones de funcionamiento son Acervo Histórico de Estado y la Casa de la Cultura Manuel Antonio López, seguido de la Biblioteca Pública Omar Baralt, Centro de Arte Maracaibo Lía Bermúdez, Casa de la Cultura Gabriel Bracho, Ateneo Fronterizo de la Guajira (FUS), Instituto Autónomo de Cultura, 
Biblioteca Pública Simón Bolívar y Biblioteca Pública Municipal $\mathrm{Br}$ Armando Colina, que presentan unas condiciones actuales de funcionamiento equivalentes. En último lugar se ubica el de la Biblioteca Pública Gilmer Fernández.

\section{Gráfico 3.}

Prueba de múltiples rangos de Tukey para los índices de alcance de las condiciones actuales de funcionamiento de los infocentros

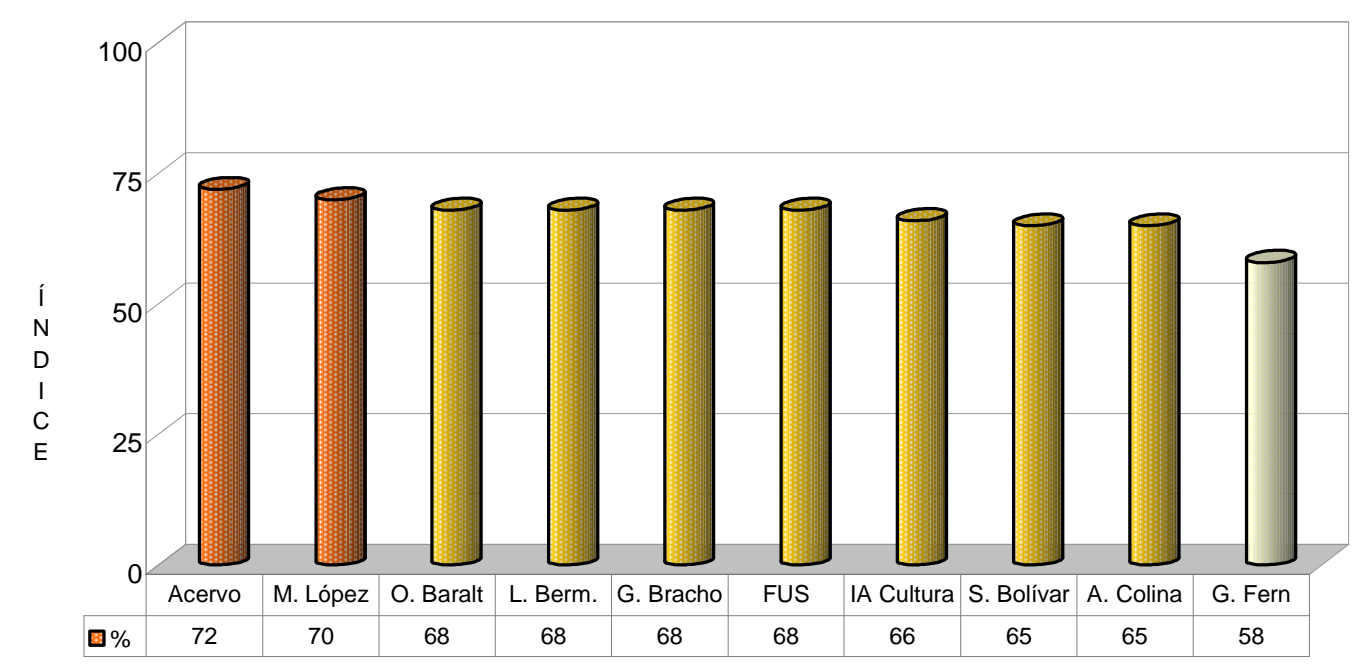

Fuente: Parra, 2004

INFOCENTRO

Estos resultados permiten expresar que de intentar, en un tiempo cercano, la mejoría de las condiciones de funcionamiento, en orden de prioridad se le haría al de la Biblioteca Pública Gilmer Fernández, y por último el del Acervo Histórico de Estado.

En relación con el objetivo 3, dirigido a establecer el nivel de democratización de los servicios educativos, se considera como moderadamente inadecuado. Esto obedece al promedio obtenido entre los índices de alcance resultantes de sus indicadores: capacitación académica, actualización académica, formación para el trabajo, crecimiento personal, formación ciudadana y comunitaria y, generación de contenidos educativos que resultó ser de $31.43+/-35.05 \%$. Para ver si los indicadores de la dimensión nivel de democratización de los servicios educativos difieren significativamente entre sí, se le aplicó ANOVA resultando que no existen diferencias significativamente entre ellos ya que el valor de $F=0.15$ con Sig. $=0.9785$ no es significativo a $p$ menor a 0.01 .

Estos resultados indican que la capacitación académica, actualización académica, formación para el trabajo, crecimiento personal, formación ciudadana y comunitaria y 
generación de contenidos educativos es muy baja con respecto al índice de alcance óptimo para ellos, tal como lo muestra el Gráfico 4.

Los resultados indican que los usuarios reciben moderadamente inadecuados cursos de actualización académica, programas de formación según las necesidades locales y regionales, cursos de crecimiento personal, cursos de formación ciudadana y comunitaria, elaboración de contenidos especializados en áreas educativas y sobre oportunidades de negocio ofrecidos por el Proyecto Infocentros (CNTI, 2000). Se manifiesta que casi no existe un acercamiento e intercambio entre la comunidad científica con los usuarios mediante el acceso a grupos de noticias, listas de correos y foros.

\section{Gráfico 4. \\ Índices de alcance de los indicadores de la democratización de los servicios educativos}

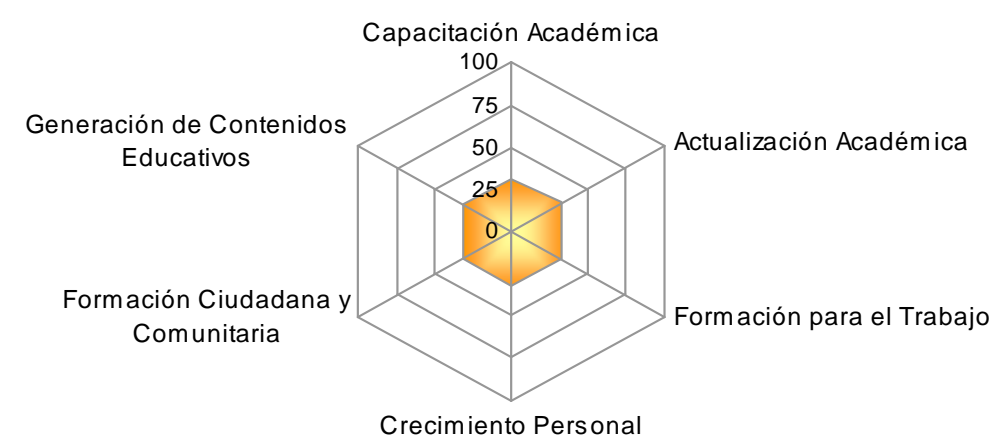

Fuente: Parra, 2004

Los resultados de este estudio coinciden con los puntos críticos encontrados en los I, II, III Encuentros Regionales de Telecentros de América Latina y el Caribe (Fundación Chasquinet, 2004), los cuales manifiestan la carencia de estrategias claras para usar la Internet con fines de desarrollo, de planes educativos que apoyen las necesidades básicas, de generación de contenidos propios y locales y, del vínculo estrecho entre escuela e infocentro.

Asimismo, los resultados de la investigación coinciden con los de Ugas y Cendrós (2007), los cuales evidenciaron una infraestructura de acceso a Internet inadecuada, escasos contenidos venezolanos en Internet que no estimulan la interacción con las páginas Web y una baja infocultura reflejo del alto nivel de analfabetismo tecnológico de los ciudadanos. También Martínez (2003) demostró que la red Internet es utilizada para trabajos de investigación y como apoyo a las cátedras impartidas en el Núcleo Costa Oriental del 
Lago de la Universidad del Zulia, tal como se manifiesta en esta investigación, al encontrar que la mayoría de los estudiantes acuden sólo en búsqueda de información. Verdú (1998) encontró, al igual que en esta investigación, la necesidad de definir una nueva escuela de la sociedad de la información basada en la tele-educación, la cual crea un nuevo espacio virtual abierto al conocimiento y al medio rural como el escenario más adecuado para su aplicación intensiva con enormes posibilidades.

A pesar de que los indicadores del nivel de democratización de los servicios educativos no difieren entre sí ya que todos son moderadamente inadecuados, el ANOVA ratifica que sí existen diferencias altamente significativas en cuanto a esta dimensión ( $F=3.241$ con Sig. $=$ $0.001<0.01$ ) con respecto a los infocentros, siendo los del Ateneo Fronterizo de la Guajira (FUS), Biblioteca Pública Simón Bolívar y Casa de la Cultura Manuel Antonio López los centros más críticos en este aspecto porque los índices alcanzados por ellos, menores a $25 \%$, los clasifican como inadecuados. Los restantes centros son considerados como moderadamente inadecuados ya que sus índices están entre $25,01 \%$ y $50 \%$ como lo muestra el Gráfico 5; sin embargo, se distinguen dos grupos diferenciados estadísticamente.

\section{Gráfico 5.}

Prueba de múltiples rangos de Tukey para los índices de alcance de la democratización de los servicios educativos

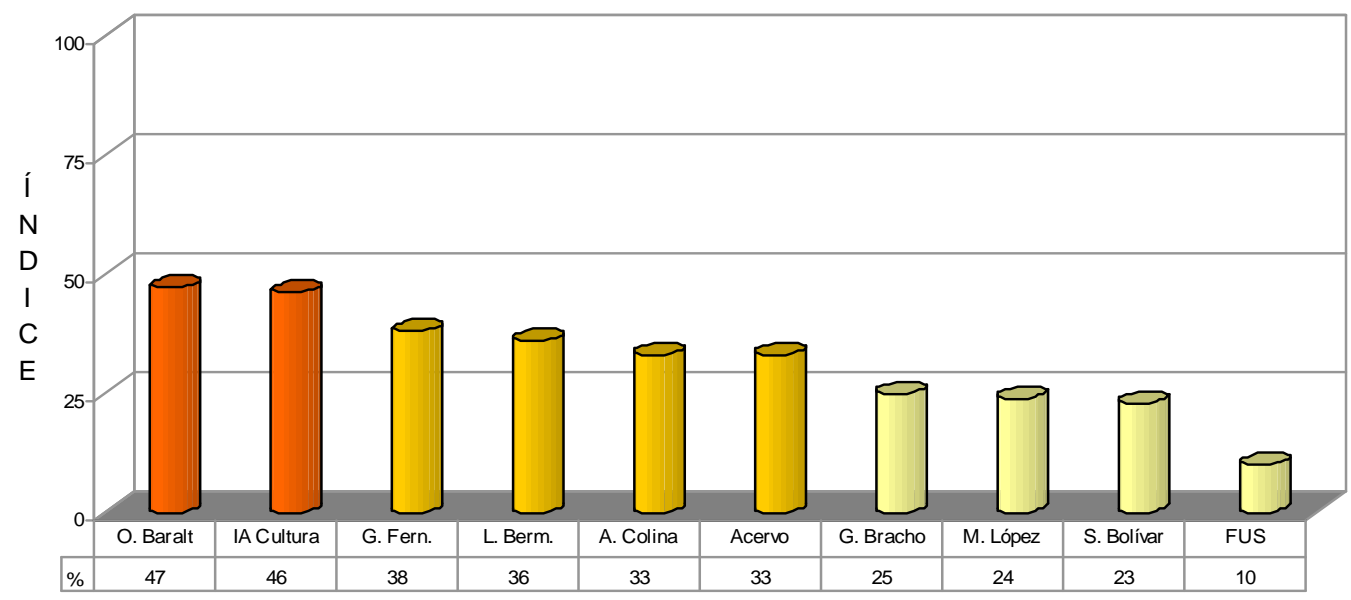

Fuente: Parra, 2004

En relación con el objetivo 4, dirigido a determinar la sustentabilidad del programa, se puede categorizar como moderadamente adecuada al lograr un índice de alcance de $56+/$ $4.61 \%$, debido al promedio obtenido entre los índices de alcance resultantes de sus indicadores: asociatividad, competitividad y expansividad, los cuales difieren 
significativamente entre sí ya que se les aplicó ANOVA, resultando el valor de $\mathrm{F}=2080$ con Sig. $=0.0000$ menor a 0.01 . Tal diferencia se discrimina aplicando la prueba de Tukey. La expansividad es el indicador que mejor expresa a la sustentabilidad, seguido y diferenciándose estadísticamente de la competitividad y en último lugar se sitúa la asociatividad. Los dos primeros se consideran moderadamente adecuados y el último moderadamente inadecuado.

Estos resultados coinciden con los de I, II y III Encuentros Regionales de Telecentros de América Latina y el Caribe (Fundación Chasquinet, 2004), en tener como puntos críticos: el espacio de participación en la toma de decisiones urbanas, la identificación de instituciones que permitan el acceso a las TICs, la inexistencia de proyectos comunitarios, la falta de estrategias para involucrar a la comunidad en el trabajo para la transformación de los mismos y la información, experiencias y vivencias dadas en cada uno local e internacionalmente. También concuerdan con los resultados de Alfonzo (2001) en la necesidad de buscar esfuerzos para vincular funciones entre organizaciones, motivar la participación de los usuarios y anfitriones en actividades de interés para todos, resolver problemas de desarticulación institucional y de escasa vinculación con su entorno; a la vez, encontró discrepancias entre la oferta y la demanda de las necesidades del infocentro y la comunidad, el entorpecimiento de la labor por excesivas tendencias partidistas (partido político), limitados recursos financieros, escasa supervisión y control, insuficientes estímulos e incentivos para promover productividad, innovación y competitividad, carencia en algunos servicios y cursos y los que tienen están basados solo en intereses de los anfitriones y no en demandas sociales.

Asimismo, corroboran el criterio de Assenza (1999), quien afirma que debe existir una correlación entre las necesidades materiales, psicológicas, sociales y trascendentes del contexto y las ofertas de un centro de formación y además, entre las necesidades del centro y las posibilidades ofrecidas por los diversos actores sociales de la comunidad. También concuerdan con Proenza (2002) al considerar la competitividad como la principal fuerza impulsora del crecimiento en los servicios y determinante de la calidad y los precios.

Igualmente, los resultados demuestran que existe la sincronización para generar el "Diamante Competitivo" de Porter (1993), por lo cual los infocentros tienen capacidad para agruparse como sociedades con el fin de organizar su cadena de valor (generación de conocimiento) en un bloque competitivo. Asimismo, coincide con los resultados de García (2002) manifestando que éstos pueden innovar circunstancias motivadoras y de calidad para los usuarios de manera de hacerlos más competitivos. Asimismo, estos resultados coinciden 
con los hallados por Verdú (1998) referente a la necesidad de implementar una infraestructura de red basada en nuevos medios de más capacidad que permitan el acceso integrado a diversos tipos de servicios educativos de multimedia con una calidad aceptable y con unos costos razonables como medio de sustentabilidad.

Piñero (1998) encontró, al igual que esta investigación, la concepción de una planificación interactiva como escenario de futuro, en donde además del Estado, otros actores involucrados participen de manera sinérgica a través de mecanismos y acciones estratégicas que funcionen a nivel macro, meso y micro institucional, permitiendo así una orientación propia y autosostenida del desarrollo socio-económico en Venezuela. Los resultados manifiestan una coincidencia con los de Proenza y otros (2001), al revelar que un modelo de infocentros para expandirse, requiere ser adaptable a condiciones variadas con relativa facilidad.

Por otro lado, el ANOVA indica que la sustentabilidad del programa es diferencial entre cada uno de los infocentros ya que el valor de $F=60.58$ con Sig. $=0.000$ es significativo a $p$ menor a 0.01, situación que lleva directamente a aplicar sobre los resultados la prueba de múltiples rangos de Tukey (Gráfico 7). Los resultados del estudio indican que la sustentabilidad se separa en tres grupos estadísticamente diferenciados: uno conformado por Ateneo Fronterizo de la Guajira (FUS), que por tener un índice de alcance de sustentabilidad del $44.84 \%$, se considera moderadamente inadecuado, y dos grupos restantes que como se observa en el Gráfico 7, se diferencian estadísticamente pero desde los criterios del baremo del Cuadro 3 , son considerados como moderadamente adecuados.

\section{Gráfico 7. \\ Prueba de múltiples rangos de Tukey para los índices de alcance de la sustentabilidad}

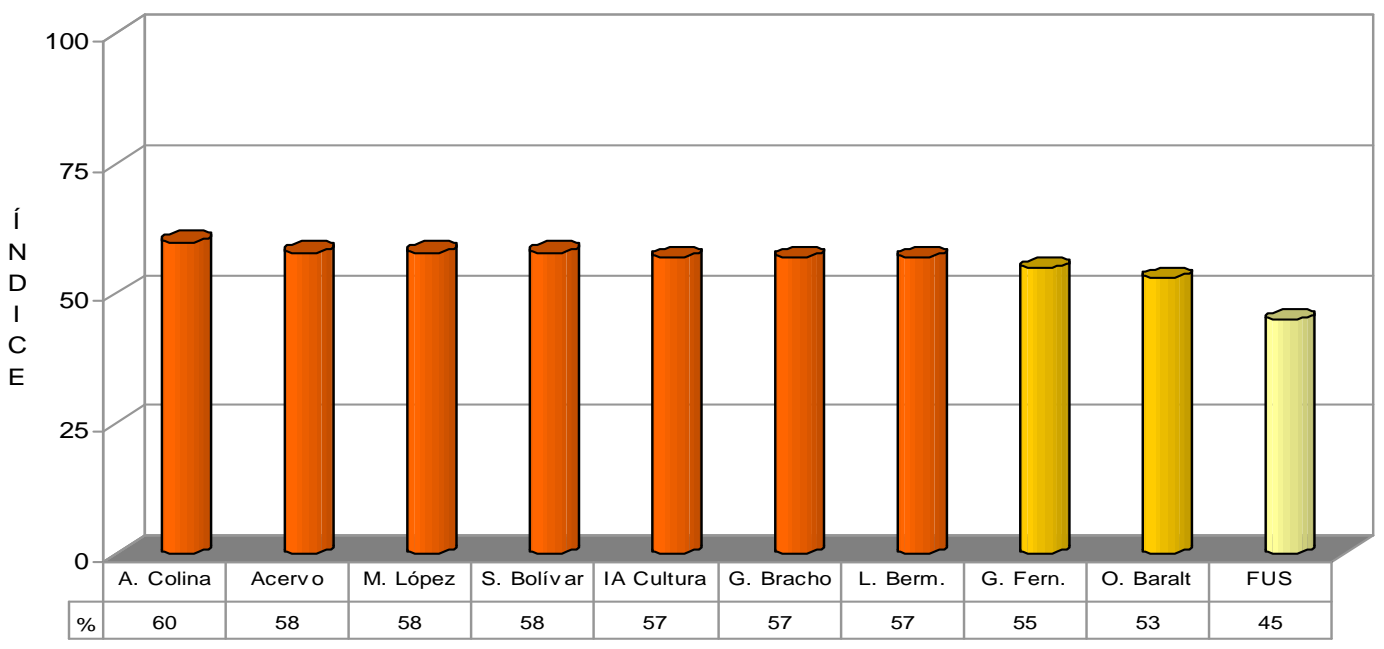

Fuente: Parra, 2004 INFOCENTRO 
Finalmente, la variable gestión educativa es el reflejo del comportamiento de sus dimensiones: filosofía de gestión, condiciones actuales de funcionamiento, democratización de los servicios educativos y sustentabilidad del programa y por lo tanto, el promedio de ellas hace que se logre un índice de alcance $54.48 \%+/-9.35 \%$, parámetro con el cual se puede catalogar como moderadamente adecuada.

El comportamiento de la dimensiones dentro de la variable gestión educativa lo presenta el ANOVA ( $F=175.79$ significativo a $p<0.01$ ) que indica que existen diferencias altamente significativas entre ellas, lo cual obedece a que las condiciones actuales de funcionamiento se diferencian de la filosofía de gestión, luego está la sustentabilidad, la cual a su vez se distingue de la democratización de los servicios educativos, que en definitiva es la dimensión con mayor desventaja en la gestión educativa (Gráfico 8).

\section{Gráfico 8.}

\section{Prueba de múltiples rangos de Tukey para los índices de alcance de las dimensiones de la gestión educativa}

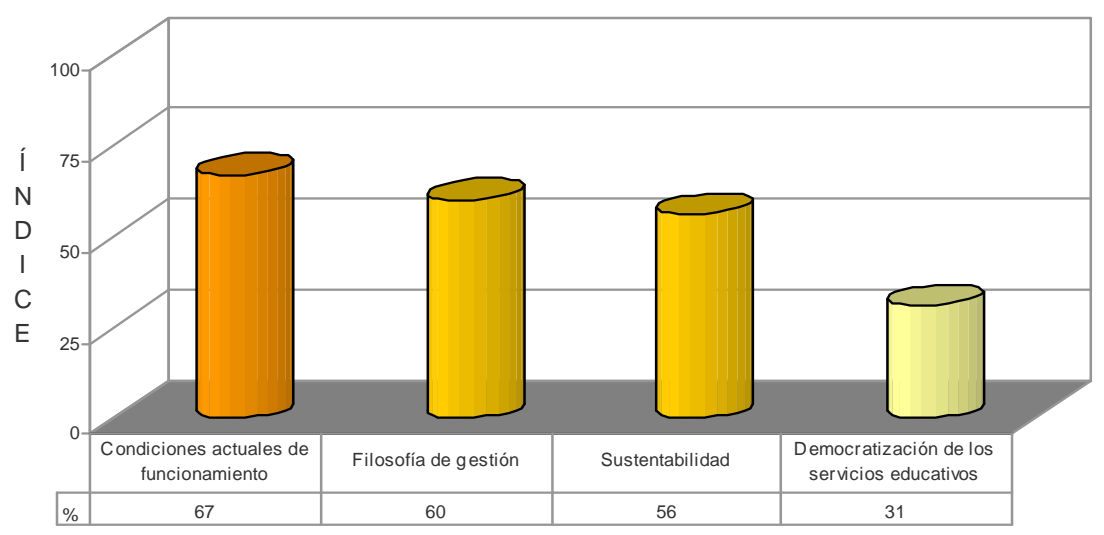

Fuente: Parra, 2004

DIMENSIÓN

En cuanto a la gestión educativa diferenciada, el ANOVA indica una diferencia significativa entre ellos $(F=3.076$ significativo a $p=0.002)$, lo cual obedece a que el Ateneo Fronterizo de la Guajira (FUS) tiene el menor índice de alcance (45.6\%) constituido por ello como el único con una gestión moderadamente inadecuada. El segundo grupo lo constituyen el resto resaltando que todos logran un índice de alcance por debajo de la media del intervalo de clase (62.5\%) que les tipifica como moderadamente adecuado, de manera que la tendencia de estos centros es hacia los niveles más bajos de la gestión moderadamente adecuada (Gráfico 9). 


\section{Gráfico 9. \\ Prueba de múltiples rangos de Tukey para los índices de alcance de la gestión educativa}

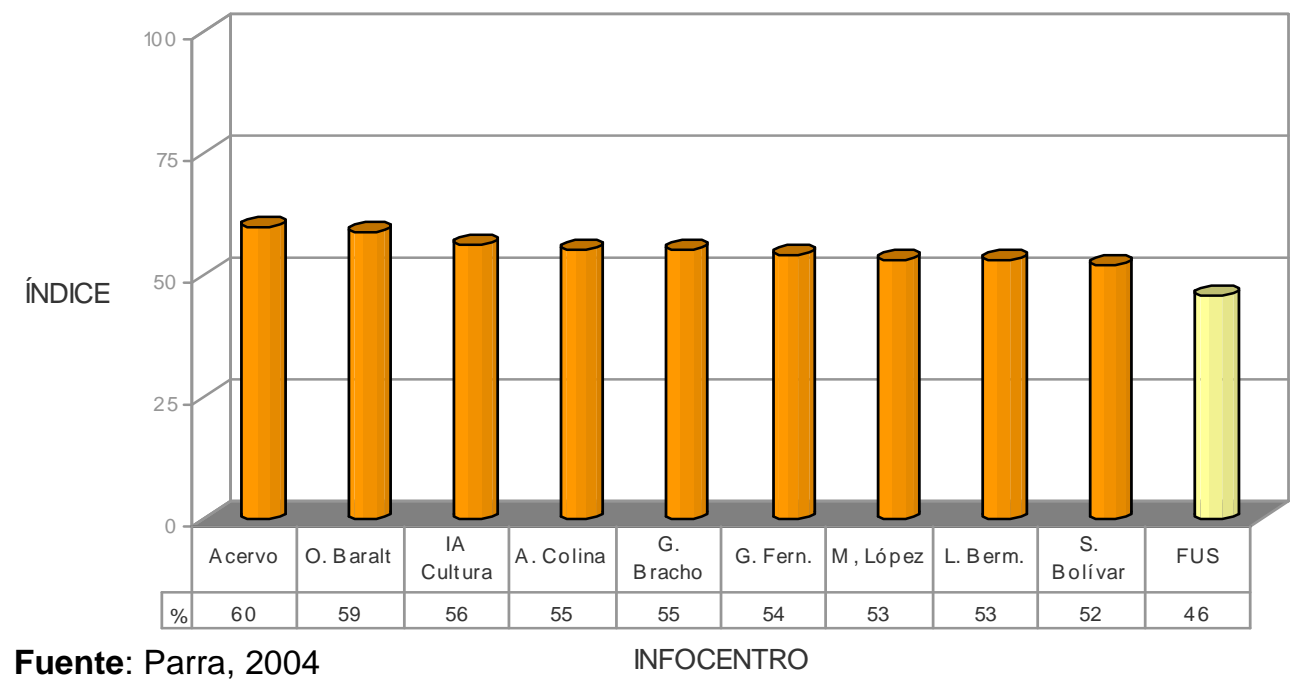

\section{Conclusiones}

En la interpretación de la filosofía de gestión del PI, para confirmar su naturaleza se evidenció que el éxito está estructuralmente debilitado, pues los entes gubernamentales no se identifican plenamente con el proyecto, por lo cual peligra su existencia.

El diagnóstico de las condiciones actuales de funcionamiento permitió detectar su situación crítica en mantenimiento, siendo sus fuentes de financiamiento, recursos humanos e infraestructura física las más sólidas. Los infocentros Acervo Histórico de Estado y Casa de la Cultura Manuel Antonio López son los que tienen mejores condiciones actuales de funcionamiento y la Biblioteca Pública Gilmer Fernández las más deficientes.

La mayoría presentan serios problemas con su ubicación ya que ésta se hizo sin atender al reglamento establecido por el CNTI y sin conversaciones con las comunidades que pretendía beneficiar. Hay una falta de continuidad en la capacitación a los anfitriones después de la inicial realizada por el CNTI y ausencia de capacitación en cuanto a los aspectos de gestión y administración. Asimismo, los anfitriones enfrentan serios problemas con su remuneración salarial.

En el área de Servicios de Información y Comunicación resultaron ser los servicios ofrecidos: el correo electrónico, búsqueda y recuperación de información y los servicios no ofrecidos: acceso a grupos de noticias, listas de correos y foros. Tampoco se brindan los 
programas de formación, programas de adiestramiento y de búsqueda y elaboración de contenidos especializados en áreas educativas y sobre oportunidades de negocio en el Área de Servicios Educativos y de Capacitación. No existen estrategias claras para usar la Internet con fines de desarrollo, no hay planes educativos que apoyen las necesidades básicas, no hay generación de contenidos propios y locales, no hay un vínculo estrecho entre escuela e infocentro. Es necesaria y urgente la implantación de servicios en los infocentros del MCT en el estado Zulia en las áreas de educación.

Según su sustentabilidad, el de la Biblioteca Pública Municipal Bachiller Armando Colina resultó el más favorecido y Ateneo Fronterizo de la Guajira el menos favorecido. No existe cooperación de alguna organización, institución o empresa, hay un mediano apoyo del CNTI y muy poco de la Gobernación del estado, la cual asumió su inicio pero abandonó posteriormente. No existe comunicación entre los mismos, los cuales no tienen capacidad ni autonomía para multiplicarse en servicios, contenidos y funciones. Sin embargo, en general, los usuarios reflejan un buen nivel de aceptación, conocimiento, disposición a servirles e incluso a pagar por sus servicios, pudiendo ser ésta una alternativa válida para la sustentabilidad de los mismos.

Al evaluar la gestión educativa se observó que enfrenta un gran inconveniente con la democratización de los servicios educativos ya que se no se logra una participación de otros entes importantes como las escuelas publicas y privadas. Además las organizaciones propias de la comunidad no se integran a las actividades de los infocentros. Existe una escasa correlación entre las necesidades de las comunidades y las ofertas de los infocentros, la baja correlación también se observó entre las necesidades de los infocentros y las posibilidades ofrecidas por los diversos actores sociales de la comunidad.

En los niveles de la democratización de los servicios educativos se reflejó la carencia de muchos de ellos en las áreas de Capacitación Académica, Actualización Académica, Formación para el Trabajo, Crecimiento Personal, Formación Ciudadana y Comunitaria y Generación de Contenidos Educativos. Los infocentros Biblioteca Pública Simón Bolívar, Casa de la Cultura Manuel Antonio López y Ateneo Fronterizo de la Guajira resultaron los centros más críticos en este aspecto.

Finalmente, la gestión educativa, en general, resultó aceptable y con un gran potencial, considerando que es un programa joven y con muy buena aceptación por las comunidades y anfitriones como apoyo para el logro de sus objetivos en función de utilizar las TICs como un potencial instrumento del desarrollo endógeno, cultural, social, económico y educativo de la región y el país. 


\section{REFERENCIAS}

Alfonzo, Diana. (2001). Factores Incidentes en la Formulación de una Metodología de Planificación para la Función Investigación. Tesis Doctoral. Universidad Dr. Rafael Belloso Chacín. Decanato de Investigación y Postgrado. Doctorado en Ciencias. Maracaibo, Venezuela.

Asociación Española de Teletrabajo. (2004). Recuperado el 14 de febrero de 2004, de http://www.aet.es.

Assenza, Víctor. (1999). Competitividad es productividad, con la calidad de la educación y la formación del capital humano. Recuperado el 14 de junio de 2003, de http://www.oei.es/eduytrabajo2/productividad.PDF.

Barrera, Azael. (2002). Evaluación de gestión y propuesta de sustentabilidad de los Infocentros del Centro Nacional de Tecnologías de Información del Ministerio de Ciencia y Tecnología de la República Bolivariana de Venezuela. Recuperado el 28 de enero de 2003, de http://www.telecentros.org/comunidad/encuentros/regionalll/mercado.htm.

Brugger, Walter. (1995). Diccionario de Filosofía. Barcelona, España: Herder.

Centro Nacional de Tecnologías y de Información, CNTI - Venezuela. (2000). Proyecto Infocentros. Caracas, Venezuela.

Centro Nacional de Tecnologías y de Información, CNTI - Venezuela. (2001). Informe Anual. Caracas, Venezuela: CNTI.

Chávez, Nilda. (2001). Introducción a la investigación educativa. Maracaibo, Venezuela: La Columna.

Delors, Jacques; In'am Al Mufti; Amagi, Isao; Carneiro, Roberto; Chung, Fay; Geremek, Bronislaw; Gorham, William; Kornhauser, Aleksandra; Manley, Michael; Padrón Quero, Marisela; Savané, Marie-Angélique; Singh, Karan; Stavenhagen, Rodolfo; Myong Won. (1996). La educación encierra un tesoro: informe a la UNESCO de la Comisión internacional sobre la educación para el siglo XXI. Madrid, España: SantillanaUNESCO.

Fundación Chasquinet. (2002). Estado del Arte de los Telecentros en América Latina y el Caribe. Recuperado el 20 de enero de 2003, de http://www.telecentros.org/estarte/index.html.

Fundación Chasquinet. (2004).Somos@telecentros. Recuperado el 20 de junio de 2004, de http://www.aet.es.http://www.tele-centros.org/index.html.

García, Francisco. (2002). Evaluación de unidades didácticas de teleformación de directivos de instituciones educativas. Tesis doctoral. Departamento de Didáctica y Organización. Universidad de Granada. Recuperado el 20 de enero de 2003, de http://www.ugr.es/ sevimeco/revistaeticanet/Tesis.htm. 
Instituto Nacional de Estadística, INE - Venezuela (2002). Censo Población y Vivienda 2001. Recuperado el 15 de julio de 2004, de http://www.ocei.gov.ve/censo/fichascenso/fichacenso.asp

López, Moisés. (2002). Telecentros comunitarios: Análisis de experiencias en países en desarrollo. Proyecto fin de carrera. Departamento de Ingeniería de Sistemas Telemáticos. Universidad Politécnica de Madrid, España. Recuperado el 10 de febrero de 2003, de http://www.uib.colnodo.apc.org/documentos.html

Martínez, María. (2003). Infocentro para la Gestión del Conocimiento en el Núcleo Costa Oriental del Lago de la Universidad del Zulia. Tesis de Maestría. Universidad Dr. Rafael Belloso Chacín. Decanato de Investigación y Postgrado. Maestría en Informática Educativa. Maracaibo, Venezuela.

Ministerio de Ciencia y Tecnología de Venezuela, MCT (2001). Plan Nacional de Tecnologías de Información y Comunicación (PlanTIC). Recuperado el 13 de febrero de 2003, de http://www.mct.gov.ve/.

Organización Internacional del Trabajo, OIT. (1996). Guía para la preparación de planes de trabajo, informes de avance e informes de autoevaluación para programas y proyectos de cooperación técnica. Recuperado el 15 de julio de 2003, de http://www.ilo.org/public/spanish/bureau/program/eval/guides/wkpln/index.htm.

Parra, Doris. (2004). Gestión educativa de los Infocentros del Ministerio de Ciencia y Tecnología. Lineamientos de sustentabilidad. Tesis Doctoral. Mención publicación. Universidad Dr. Rafael Belloso Chacín. Decanato de Investigación y Postgrado. Doctorado en Ciencias de la educación. Maracaibo, Venezuela.

Piñero, María. (1998). Educación, Ciencia, Tecnología y esfuerzo productivo: Una nueva dimensión para el desarrollo de Venezuela. Tesis Doctoral. Universidad Dr. Rafael Belloso Chacín. Decanato de Investigación y Postgrado. Doctorado en Ciencias, Mención Investigación. Maracaibo, Venezuela.

Porter, Michael. (1993). La Ventaja Competitiva de las Naciones. Buenos Aires: Vergara.

Pozner, Pilar. (2000). Competencias para la profesionalización de la gestión educativa. Recuperado el 15 de junio de 2003, de http://www.iipebuenosaires.org.ar/difusion/pub 1998-2000.asp\#transformacion.

Presidencia de la República Bolivariana de Venezuela. (2000a). Decreto No. 825. Gaceta Oficial № 36.955, Recuperado el 09 de febrero de 2003, de http://www.analitica.com/bitblioteca/conatel/decreto internet.asp.

Presidencia de la República Bolivariana de Venezuela. (2000b). Ley Orgánica de Telecomunicaciones. Gaceta Oficial № 36.970, Recuperado el 10 de febrero de 2003, de http://www.tsj.gov.ve/gaceta/junio/120600/120600-36970-00.html.

Proenza, Francisco. (2002). E-ParaTodos: Una estrategia para la reducción de la pobreza en la era de la información. Recuperado el 03 de marzo de 2003, de http://www.e-paratodos.org/pdf/e-ParaTodos.pdf. 
Proenza, Francisco; Bastidas-Bush, Roberto y Montero, Guillermo. (2001). Telecentros para el desarrollo socioeconómico y rural en América Latina y el Caribe. Recuperado el 16 de febrero de 2003, de http://www.e-paratodos.org/pdf/Telecentros.pdf.

Quintero, Tahis. (2004). Comportamiento organizacional. Recuperado el 24 de marzo de 2004,

www.fing.edu.uy/catedras/OPI/Material\%20Aopyo/LS Comportamiento Organizaciona $\underline{1 \% 20 . d o c}$

Rosales, Ramón. (1997). La Asociatividad como estrategia de fortalecimiento de las Pymes. Revista Capítulos, SELA, 51, 97-119.

Ruiz, Carlos. (2002). Instrumentos de Investigación Educativa. Procedimientos para su diseño y validación. Barquisimeto, Venezuela: Centro de Investigación y desarrollo en Educación y Gerencia (CIDEG).

Ugas, Luis y Cendros, Jesús. (2007). The Digital Gap in Maracaibo City in Venezuela. Telematics and Informatics journal. 24, $41-47$. Recuperado el 09 de febrero de 2003, de www.elsevier.com/locat/tele

Verdú, María. (1998). Aplicación de Internet como nuevo espacio de formación y comunicación para los centros de primaria y secundaria. Tesis Doctoral. Universidad de Valladolid. Facultad E.T.S.I. Departamento Teoría de la Señal y Comunicación e Ingeniería Telemática. Valladolid, España. Recuperado el 19 de julio de 2003, http://www.cervantesvirtual.com/Buscar.html?texto=Tesis+doctoral\&tipoMuestra=obras OtrosCampos\&tipoObra=obraGenerica\&PO=1\&portal $=0$.

Vivas, José y Suros, Rina. (2000). Infocentros: La primera piedra del gobierno digital. Recuperado el 19 de enero de 2003, de http://www.infocentros.gov.ve/viewusuario/docs/c27/PrimeraPiedraGobiernoDigital.pdf. 